\title{
BRIEF
}

\section{Assessing Pharmacy Student Performance and Perceptions on Counseling Skills Through A Simulated Telehealth Encounter}

\author{
Sanah Hasan, PharmD, PhD, ${ }^{\mathrm{a}}$ Hamzah Al Zubaidi, PhD, ${ }^{\mathrm{b}}$ Ward Saidawi, BPharm ${ }^{\mathrm{b}}$ \\ ${ }^{a}$ Ajman University, College of Pharmacy and Health Sciences, Ajman, United Arab Emirates \\ ${ }^{\mathrm{b}}$ University of Sharjah, College of Pharmacy, Sharjah, United Arab Emirates
}

Corresponding Author: Sanah Hasan, Ajman University, College of Pharmacy and Health Sciences, Ajman, United Arab Emirates. Tel: +97150-3608206. Email: s.hasan@ajman.ace.ae

Submitted February 25, 2021; accepted September 3, 2021; ePublished September 2021

\begin{abstract}
Objective. To describe implementation of a patient counseling roleplay assessment via teleconferencing platform in a newly-developed pharmacy communications course, assess student performance on the roleplay and compare it with other assessments, and measure student perceptions of and satisfaction with the experience.

Methods. Eighteen cases were developed, each belonging to one of three interactions in community pharmacy: new prescription, refill, or over-the-counter (OTC) medication request. A rubric was designed to evaluate each type of interaction. Student scores in various course assessments were tested using Spearman's rank-order. Student scores in the three cases were compared using Kruskal-Wallis $H$. Students evaluated their experience and satisfaction of the assessment and effectiveness of the course.
\end{abstract}

Results. Seventy-nine students completed the assessment with a mean score of 17.4/20 (87.0\%). Student scores in counseling roleplay were similar among case types and positively correlated with other traditional assessments in the course. Despite internet connectivity issues, and heightened student anxiety, $71.0 \%$ agreed that the assessment did not affect the quality of their counseling, and $74.0 \%$ agreed that the experience was comparable to traditional assessments. The telehealth activity led to enhanced perceived student knowledge and confidence in interviewing and counseling patients.

Conclusion. Students attained high scores that were consistent with other assessments in the course. Students reported the assessment did not affect the quality of their counseling, and felt the setting and context were still authentic. The experience required dedicated preparation and organization, but was successful in demonstrating overall student satisfaction and positive perceptions.

Keywords: patient counseling, communication skills, roleplay, telehealth, telepharmacy

\section{INTRODUCTION}

Studies have recognized that patient counseling by community pharmacists could improve adherence and patient self-care behaviors, and decrease medical costs. ${ }^{1-3}$ Counseling is 'a face-to-face interaction between the pharmacist and the patient or caregiver', although telephone, and social media and technology - based consultations have been used. ${ }^{2-4}$ Communication skills are integral to patient counseling, and pharmacists need to obtain, practice and apply communication skills to provide pharmaceutical care.

Telehealth is defined as "the use of electronic information and telecommunications technologies to support and promote long-distance clinical health care, patient and professional health-related education, public health and health administration." ${ }^{5}$ The term telehealth also includes e-health and mobile health (mHealth), and represents health services delivery through other means than face-to-face. ${ }^{6}$ There has been no universally-accepted definitions to telehealth terms, and these are likely to change over the next few years, but a proposed definition to e-health is "the intersection of medical informatics, public health and business, referring to health services and information delivered or enhanced through the Internet and related technologies." Mobile health is most commonly used in reference to "using mobile communication devices, such as mobile phones, tablet computers and personal digital assistants (PDAs), and wearable devices such as smart watches, for health services, information, and data collection." 8 Telehealth tools have proven to be effective in providing care related to public health by pharmacists in various settings. ${ }^{9-13}$ Pharmacists have provided services related to diabetes, hypertension, lipid, anticoagulation, geriatric, human immunodeficiency virus, and hepatitis $C$ using telehealth. ${ }^{14-16}$ Advantages to telehealth include convenience, access to routine care, decreased costs, and reduced exposure to disease. ${ }^{17}$ Yet, telehealth has not been implemented widely possibly due to lack of knowledge and training of both professionals and patients in the area, lack of face-toface contact, health professional perceptions of negative impact on patient care, costs associated with resourcing the technology, technical and Internet problems encountered with use, confidentiality concerns, workload and organizational support, and the inability to seek compensation for these services. ${ }^{6,18}$ Nevertheless, restrictions on 
human contact imposed by precautionary measures due to the global coronavirus disease (COVID-19) pandemic have greatly affected how heath care is provided and have accelerated the adoption of telehealth. Much of this change is believed to be permanent, and for healthcare professionals including pharmacists to deliver services using telehealth they need to be educated and trained. ${ }^{19}$ Pharmacy organizations are calling for "appropriately trained and equipped pharmacists" to use telepharmacy (the use of telehealth tools in pharmacy). ${ }^{20-22}$

This growth of telehealth has prompted health profession education to provide virtual or e-learning experiences for students; confirming improved students' knowledge, perceived confidence and learning in a number of areas. ${ }^{23-27}$ As technology becomes increasingly integrated into the classroom, and with the growth of health professions programs with multiple campuses, the use of live streaming or video recordings to reach students of these campuses has increased, which addresses time and space limitations. ${ }^{25,28-31}$ Telehealth has successfully been used in interprofessional education (IPE) whereby students obtained medication histories, provided clinical recommendations, and reported improved self-perception of interprofessional competence and attitudes toward interprofessional collaboration. ${ }^{32} \mathrm{~A}$ simulated Telehealth collaboration has been shown to reduce logistical difficulties associated with IPE integration of teams in Team-Based Learning (TBL) related to pharmacogenomics. ${ }^{33}$ Skill-based assessments have also been conducted virtually, including formative and summative OSCE; students were found to perform comparably to those conducted in-person. ${ }^{34-35}$ Several studies have been conducted to compare study behaviors and grades of students in on and off campuses licensure examinations, and have found no significant differences in learning outcomes achievement between the two. ${ }^{36-38}$

The program at Ajman University, United Arab Emirates (UAE) offers a four-year, 160-credit hour Bachelor of Pharmacy degree. The Communication Skills in Pharmacy course is a newly-offered, two-credit hour course introduced in the second semester of the program delivered in two dedicated lectures per week. The course is aimed at introducing communications skills and their application in patient care, and patient counseling and advice giving on medication use. Assessments in the course consisted of pre-class assignments, a quiz, a midterm, a written assignment, patient counseling roleplay, and a comprehensive final exam. The pre-class assignments (5.0\% weighting) aimed for students to practice gathering information about the medications covered in the course. The quiz (5.0\% weighting) consisted of a multiple choice (MC) test of information gathered in pre-class assignments. The midterm (20.0\% weighting), a mix of MC and text-type questions, covered various communication areas. The group assignment ( $20.0 \%$ weighting) was a five-page, student-scripted scenario focusing on pharmacist assertive behavior. The counseling roleplay (20.0\% weighting) assessed student performance in counseling a simulated patient presenting a new or refill prescription or an OTC request. The MC final exam (30.0\% weighting) was comprehensive covering general course content. In Spring semester, 2020, the course was offered for the first time. From January until March 15,2020 , the course was offered in-person, however, after the breakout of the COVID-19 pandemic, Ajman University adopted a complete online teaching and assessment strategy using Moodle as a learning management system (LMS). Hence, face-to-face roleplay sessions within the course were replaced with pre-selected videos of pharmacy interactions, and the patient counseling roleplay assessment was conducted using Zoom audio-visual teleconferencing (Zoom Video Communications, San Jose, CA) platform. Therefore, this project aimed to describe the implementation of a virtual patient counseling roleplay assessment in a first year Bachelor of Pharmacy communications course, to compare student performance in this and other course assessments, and to evaluate student experience with their first roleplay assignment using teleconferencing technology.

\section{METHODS}

Cases

As chronic disease management and provision of extended pharmacy services are limited in the UAE, interactions with patients mostly occur in community pharmacy. ${ }^{39}$ Hence, a total of 18 case scenarios were developed, each belonging to one of three types of interactions that occur in community pharmacy: a new or refill prescription or over-the-counter (OTC) medication request. The course instructor teamed up with a research assistant and three community pharmacists to ensure the cases were correct and logical. In addition, to ascertain that the cases had similar difficulty, team members worked to individually assign a difficulty score from one to 10 to each case, considering the complexity of the patient and the amount of counseling required; if scores were discrepant, the cases were then refined until consensus was achieved. Students were divided into groups of 10, leading to eight sessions conducted on different days. Two different cases were used in each session to total 16 cases; the two remaining cases were kept for contingency. Each of the 16 cases was assigned a number (from one to 16), and students were assigned a case by assigning the numbers from one to 16 to the 79 students according to their sequence on the class roster obtained from the Registration Department at the University; after the $16^{\text {th }}$ case was assigned, the same process was repeated until all students were assigned to a case. Students were not made aware of their case type allocation.

\section{Evaluation Rubrics}


For each of the three case types, an evaluation rubric was developed to suit the interaction. ${ }^{40-42}$ The rubric included items with variable weighting, related to opening an interaction totaling four points, information gathering totaling four points, information giving totaling six points, closing an interaction totaling three points, and communication skills totaling three points (Table 1). The items were graded based on the scale: (zero = not addressed; half the mark if partially completed; full mark if fully completed).

Student post assessment evaluation: On a five-point Likert-type scale of one = strongly disagree, to five = strongly agree, students evaluated the case content, their experience with the counseling roleplay assessment, and the logistics associated with it. They also rated their satisfaction with the assessment and the effectiveness of the course.

The patient counseling roleplay assessment

To help alleviate the anxiety and ambiguity surrounding a new assessment approach, several live sessions were led by the course instructor on the LMS to review expectations from students, the evaluation rubrics and student distributions to the sessions. Participation in all course activities and assessments was required from all students, however, participation in the surveys post the roleplay assessment was optional, and the students were well aware of that. In addition, a mock roleplay session covering each interaction type was conducted and recorded on Moodle for student convenient access and review.

On the actual day of the assessment, students interacted on Zoom via high-speed internet using their own computer devices with a webcam. The following steps summarized the sequence of events on each day of assessment:

Step 1: A session on the LMS was started for communication with students outside zoom before and after role play.

Step 2: A Zoom session was initiated, and students were called in to join the session individually.

Step 3: The student was admitted to the session, and he/she conducted their interaction with the simulated patient (role played by a trained research assistant). Each student was allowed a maximum of 10 minutes to complete their interaction. The session was digitally recorded on Zoom.

Step 4: When finished, the student was asked to leave and, if agreeing, to go back to the LMS to complete a post assessment survey that was linked online to SurveyMonkey.

Step 5: The procedure was repeated for all eight assessment days until all students were evaluated.

Step 6: At the end of all sessions, the instructor conducted a group debriefing for students and gave feedback on the optimal management of the cases and on student performance.

Step 7: The instructor reviewed recordings of all sessions (which were also available to the students on their demand), and assigned grades by filling out the respective rubric for each student.

\section{Data analysis}

Stata Version 15 (StataCorp, College Station, Texas, USA) was used for data analysis. Continuous variables such as students' scores in various assessments were presented as means and standard deviations (SD), while ordinal variables such as post assessment evaluations were presented using counts and frequencies. Weighted means were also calculated for ordinal variables by assigning numerical values to response options and using their counts. Students' scores in various assessments were tested using the Shapiro-Wilk test and were found not to follow a normal distribution. The Kruskal-Wallis $H$ was used to test differences in students' scores in the counseling cases. Spearman's rank-order correlation coefficient was used to test correlations between students' scores in the counseling roleplay and other assessments in the course. A p-value <.05 was considered statistically significant.

\section{RESULTS}

All 79 students completed the counseling roleplay assessment. Almost half of the students (36 (45.6\%)) achieved a B (80.0-89.9\%) while $22(27.9 \%)$ and $15(19.0 \%)$ achieved C (70.0-79.9\%) and A ( $\geq 90.0 \%)$, respectively. Mean scores in all course assessments are shown in Table 2.

No significant differences were found among students' scores in the three case types $\left(X^{2}=4.86, p=.089\right)$. Notably, scores in the counseling roleplay were significantly associated with scores of patient counseling questions in the Final examination $\left(\mathrm{r}_{\mathrm{s}}=0.26, p=.020\right)$ the overall Final examination scores $\left(\mathrm{r}_{\mathrm{s}}=0.40, p<.001\right)$ and the Midterm $\left(\mathrm{r}_{\mathrm{s}}=0.25, p\right.$ $=.024)$.

Fifty-four students $(68.4 \%)$ completed the post assessment survey. The majority agreed that the cases assessed specific knowledge areas in communications, however, 50.0\% of students agreed that it was more stressful than traditional written examinations (Table 3). Most students reported that the assessment was well administered, that they were well informed of what they needed to do, and that the time provided was adequate. Furthermore, $71.2 \%$ of students agreed or strongly agreed that use of a virtual assessment did not affect the quality of their counseling, $75.0 \%$ agreed or strongly agreed that the experience was comparable to traditional in-person assessments, and $70.6 \%$ felt the setting and context were still authentic (Table 3). Most students reported that they were satisfied with the counseling roleplay; two-thirds $(66.1 \%)$ reported that they looked forward to doing more exercises virtually in the future (Table $3)$. 


\section{DISCUSSION}

To our knowledge, this was one of early studies to describe the implementation of a patient counseling roleplay assessment using teleconferencing technology in pharmacy curriculum. Our findings support available evidence that assessed the effectiveness of e-learning in pharmacy education. ${ }^{25}$ Recently, patient counseling and communication skills were assessed via virtual platforms whereby students and faculty considered the virtual assessment appropriate in assessing student communication skills, however, a strong preference for future virtual skills-based assessments was not observed. ${ }^{35}$ In our study, despite reported anxiety with a new assessment, students were very satisfied and looked forward to undergoing similar assessments in the future. We think that the rigorous process adopted in developing the case scenarios and associated evaluation rubrics, in addition to student orientation and session piloting were instrumental in assuring student familiarity with the new assessment and the level of performance expected from them. Despite these positive outcomes on student learning and satisfaction, there is an overall paucity of research to demonstrate the true benefits of pharmacists' services utilizing telehealth. However, early evidence shows that telehealth may be an effective way to deliver pharmacist services and to improve patient care, including enhancing adherence to medications and achieving glycemic control in diabetes. ${ }^{43-45}$

The integrity of assessment, however, has been debated as one of the challenges with e-learning. ${ }^{46}$ Integrity mechanisms for online delivery of assessment are being explored and evolve as our knowledge of the technology increases ${ }^{34}$ Of note in this assessment, student scores were similar and correlated well with other conventional assessments in the course. Integrity mechanisms used in this study included student awareness that a variety of cases were developed to reduce intentional broadcast of cases, using more than one case per session, random assignment of students to cases, limiting the examination administration time and feedback was withheld until all students had completed the assessment.

Zoom offered a feasible option to conduct the roleplay assessment given its various functionalities, ease of use, familiarity of users with the technology and its free-of-charge availability to the faculty and students. ${ }^{47-49}$ As it is already used by our university, no additional costs were incurred to use this tool. Clearly, there are other free or lowcost video/chat applications available to academic departments if a teleconferencing system cannot be afforded. The rapid spread of the COVID-19 outbreak imposed sudden changes in almost all aspects of modern life, including higher education. This rapid transition to distance e-learning raised questions about the ability of faculty to efficiently use technologies in teaching and assessment. ${ }^{50}$ This study demonstrated that the faculty can efficiently and effectively adapt to e-learning modalities with adequate preparation; students were very satisfied with their experience in the course.

\section{Limitations}

Although a rigorous process was used to develop and pilot the rubrics, they have not undergone psychometric testing and validation. This novel experience required ample faculty and student preparation, smoothening of logistics and great organization. Several students needed to access additional devices with quality video and audio capabilities to undergo the assessment. Despite that internet connectivity problems were predominantly addressed before the actual assessment, some were still for a minority of students.

\section{CONCLUSION}

Students attained high scores in all components of the communication skills and counseling virtual assessment. Student scores in counseling roleplay were correlated with similar traditional assessments in the course. Students reported the assessment did not affect the quality of their counseling, that the experience was comparable to traditional in-person assessments; they felt the setting and context were still authentic. Students reported improved knowledge, communication skill and confidence in counseling patients. Despite some anxiety, most students evaluated their experience positively and looked forward to undergoing similar assessments conducted virtually in the future.

\section{ACKNOWLEDGMENTS}

The authors wish to thank the community pharmacists Dalal Taweel, Asma Khadr and Rami Ahmed who participated in case development and validation and the pilot session.

\section{REFERENCES}

1. Bunting BA, Smith BH, Sutherland SE. The Asheville Project: clinical and economic outcomes of a community-based long-term medication therapy management program for hypertension and dyslipidemia. $J$ Am Pharm Assoc. 2008 48(1):23-31.

2. Blom L, Krass I. Introduction: the role of pharmacy in patient education and counseling. Patient Educ Couns. 2011 83(3):285-287. doi:10.1016/j.pec.2011.05.021

3. Kooij MJ, Heerdink ER, van Dijk L, van Geffen EC, Belitser SV, Bouvy ML. Effects of telephone counseling intervention by pharmacists (TelCIP) on medication adherence; results of a cluster randomized trial. Front. 
Pharmacol. 2016 7:269.

4. Kretchy IA, Asiedu-Danso M, Kretchy JP. Medication management and adherence during the COVID-19 pandemic: perspectives and experiences from low-and middle-income countries. Res Social Adm Pharm. 2020. S1551-7411(20)30332-6. doi: 10.1016/j.sapharm.2020.04.007.

5. The Office of the National Coordinator for Health Information Technology. Telemedicine and Telehealth. https://www.healthit.gov/topic/health-it-health-care-settings/telemedicine-and-telehealth. Published September 24, 2020. Accessed March 28, 2021.

6. Kayyali R, Hesso I, Mahdi A, Hamzat O, Adu A, Nabhani Gebara S. Telehealth: Misconceptions and experiences of healthcare professionals in England. Int J Pharm Pract. 2017 25;203-209.

7. Eysenbach G. What is e-health? J Med Internet Res. 2001 3(2):E20. doi:10.2196/jmir.3.2.e20

8. Cipresso P, Serino S, Villani D, et al. Is your phone so smart to affect your states? An exploratory study based on psychophysiological measures. Neurocomputing. 2012 84: 23-30.

9. Jeminiwa R, Hohmann L, Qian J, Garza K, Hansen R, Fox BI. Impact of eHealth on medication adherence among patients with asthma: A systematic review and meta-analysis. Respir Med. 2019 149:59-68.

10. Dumit EM, Novillo-Ortiz D, Contreras M, Velandia M, Danovaro-Holliday MC. The use of eHealth with immunizations: An overview of systematic reviews. Vaccine. 2018 36:7923-7928.

11. McCarroll R, Eyles H, NiMhurchu C. Eff ectiveness of mobilehealth (mHealth) interventions for promoting healthy eating in adults: A systematic review. Prev Med. 2017 105:156-168.

12. Greenwood DA, Gee PM, Fatkin KJ, Peeples M. A Systematic Review of Reviews Evaluating TechnologyEnabled Diabetes Self-Management Education and Support. J Diabetes Sci Tech. 2017 11:1015-1027.

13. McIntosh JRD, Jay S, Hadden N, Whittaker PJ. Do E-health interventions improve physical activity in young people: A systematic review. Public Health. 2017 148:140-148.

14. Bellfi L, Young J, Pratt L, Patel A, Mei D, Chan J. Sustained virologic response with peginterferon plus ribavirin in the Illinois prison population infected with hepatitis $\mathrm{C}$ virus through telemedicine: a retrospective chart review. Pharmacotherapy. 2016 36(12).

15. Shane-McWhorter L, Lenert L, Petersen M, et al. The Utah remote monitoring project: Improving health care one patient at a time. Diabetes Technol Ther. 2014 16(10):653-660. doi:10.1089/dia.2014.0045

16. McFarland M, Davis K, Wallace J, et al. Use of home telehealth monitoring with active medication therapy management by clinical pharmacists in veterans with poorly controlled type 2 diabetes mellitus. Pharmacotherapy. 2012 32(5):420-426. doi:https://doi.org/10.1002/j.1875-9114.2011.01038.x

17. Smith A, Thomas E, Snoswell C, et al. Telehealth for global emergencies: Implications for coronavirus disease 2019 (COVID-19). J Telemed Telecare. 2020 26(5):309-313. doi:10.1177/1357633X20916567

18. Pritchard RI, Huff J, Scheinberg N. Impact of regulatory changes on pharmacist-delivered telehealth during the COVID-19 pandemic. J Am Pharm Assoc (2003). 2020 60(6):e76-e79.

19. Crilly P, Kayyali R. A systematic review of randomized controlled trials of telehealth and digital technology use by community pharmacists to improve public health. Pharmacy (Basel). 2020 8(3):137. doi:10.3390/pharmacy8030137

20. Badowski ME, Walker S, Bacchus S, et al. ACCP White Paper. Providing comprehensive medication management in telehealth. Pharmacotherapy. 2018 38(2):e7-e16. doi:https://doi.org/10.1002/phar.2071

21. Alexander E, Butler C, Darr A, et al. ASHP statement on telepharmacy. ASHP statement on telepharmacy. Am J Health Syst Pharm. 201774 (9):e236-41.

22. American Pharmacists Association. Telehealth in your pharmacy practice. Using innovative technology to care for patients during COVID-19. https://aphanet.pharmacist.com/sites/default/files/audience/APhACOVID19Telehealth0620_web.pdf. Published June 1, 2020. Accessed August 29, 2021.

23. Frehywot S, Vovides Y,Talib Z, Mikhail N, Ross H, Wohltjen H, et al. E-learning in medical education in resource constrained low- and middle-income countries. Hum Resour Health. 2013 11:4. doi:10.1186/14784491-11-4

24. Hamilton LA, Franks A, Heidel RE, McDonough SLK, Suda KJ. Assessing the Value of Online Learning and Social Media in Pharmacy Education. Am J Pharm Educ. 2016 80(6):97. doi:10.5688/ajpe80697

25. Salter SM, Karia A, Sanfilippo FM, Clifford RM. Effectiveness of E-learning in pharmacy education. Am J Pharm Educ. 2014 78(4): 83. doi:10.5688/ajpe78483

26. NB Berman, SJ Durning, MR Fischer, S Huwendiek, MM Triola. The role for virtual patients in the future of medical education. Acad Med. 2016 91(9):1217-1222

27. JY Feng, YT Chang, HY Chang, WS Erdley, CH Lin, YJ Chang. Systematic review of effectiveness of situated e-learning on medical and nursing education Worldviews Evid Based Nurs. 2013 10(3):174-183

28. Martin B, Haennel J, Daniels J. Academic and clinical performance of entry-level students who attended a satellite campus using a distributed learning model. Physiother. 2015 101(Supplement 1):eS955-eS956.

29. McKendree J. Can we create an equivalent educational experience on a two campus medical school? Med 
Teach. 2009 31:e202-e205.

30. Vaccani J, Javidnia H, Humphrey-Murto S. The effectiveness of webcast compared to live lectures as a teaching tool in medical school. Med Teach. 2016 38:59-63.

31. Harrison LC, Congdon HB, DiPiro JT. The status of US multi-campus colleges and schools of pharmacy. Am J Pharm Educ. 2010 74(7):124.

32. Begley K, O’Brien K, Packard K, Castillo S, Haddad AR, Johnson K, et al. Impact of Interprofessional Telehealth Case Activities on Students' Perceptions of Their Collaborative Care Abilities. Am J Pharm Educ. 2019 83(4):6880.

33. Quesnelle KM, Bright DR, Salvati LA. Interprofessional education through a telehealth team based learning exercise focused on pharmacogenomics. Curr Pharm Teach Learn. 2018 10(8):1062-1069

34. Updike WH, Cowart K, Woodyard JL, Serag-Bolos E, Taylor JR, Curtis SD. Protecting the Integrity of the Virtual Objective Structured Clinical Examination. Am J Pharm Educ 2021:8438.

35. Van Langen KM, Sahr MJ, Salvati LA, Meny LM, Bright DR, Sohn M. Viability of Virtual Skills-based Assessments Focused on Communication. Am J Pharm Educ. 2021:8378

36. Lenz TL, Monaghan MS, Wilson AF, Tilleman JA, Jones RM, Hayes MM. Using performance-based assessments to evaluate parity between a campus and distance education pathway. Am J Pharm Educ. 2006 70(4):90.

37. Congdon HB, Nutter DA, Charneski L, Butko P. Impact of hybrid delivery of education on student academic performance and the student experience. Am J Pharm Educ. 2009 73(7):121.

38. Ried LD, McKenzie M. A preliminary report on the academic performance of pharmacy students in a distance education program. Am J Pharm Educ. 2004 68(3):65.

39. Alzubaidi H, Saidawi W, Mc Namara K. Pharmacist views and pharmacy capacity to deliver professional services in the United Arab Emirates. Int J Clin Pharm. 2018 40:1106-1115. https://doi.org/10.1007/s11096018-0662-4

40. Beardsley R, Kimberlin C, Tindall W. Communication Skills in Pharmacy Practice: A Practical Guide for Students. $6^{\text {th }}$ ed. Philadelphia, PA: LWW; 2012.

41. Horton N, Payne KD, Jernigan M, Frost J, Wise S, Klein M, et al. A standardized patient counseling rubric for a pharmaceutical care and communications course. Am J Pharm Educ. 2013 77(7):152. doi:10.5688/ajpe777152

42. Rutter PM, Horsley E, Brown DT. Evaluation of community pharmacists' recommendations to standardized patient scenarios. Ann Pharmacother. 2004 38(6):1080-1085. doi:10.1345/aph.1D519

43. Kane-Gill SL, Niznik JD, Kellum JA, et al. Use of telemedicine to enhance pharmacist Services in the Nursing Facility. Consult Pharm. 2017 32(2):93-98.

44. Abughosh SM, Wang X, Serna O, et al. A pharmacist telephone intervention to identify adherence barriers and improve adherence among nonadherent patients with comorbid hypertension and diabetes in a Medicare advantage plan. J Manag Care Spec Pharm. 2016 22(1):63-73.

45. Suksomboon N, Poolsup N, Nge YL. Impact of phone call intervention on glycemic control in diabetes patients: a systematic review and meta-analysis of randomized, controlled trials. PLoS One. 2014 9(2):e89207.

46. Assareh A, Bidokht MH. Barriers to e-teaching and e-learning. Procedia Comput Sci. 2011 3:791-795. doi.org/10.1016/j.procs.2010.12.129.

47. Major S, Sawan L, Vognsen J, Jabre M. COVID-19 pandemic prompts the development of a Web-OSCE using Zoom teleconferencing to resume medical students' clinical skills training at Weill Cornell Medicine-Qatar. BMJ Simul Technol Enhanc Learn. 2020 0:1-2. doi:10.1136/bmjstel-2020-00062.

48. Gatwood J, Hohmeier K, Farr G, Eckel S. A Comparison of Approaches to Student Pharmacist Business Planning in Pharmacy Practice Management. Am J Pharm Educ. 2018 82(5):6279. doi:10.5688/ajpe6279.

49. Halpin PA, Lockwood MKK. The use of Twitter and Zoom videoconferencing in healthcare professions seminar course benefits students at a commuter college. Adv Physiol Educ. 2019 43(2):246-249. doi:10.1152/advan.00017.2019.

50. Wendelboe AM, Miller M, Drevets D, Salinas L, Miller EJ, Jackson D, et al. Tabletop exercise to prepare institutions of higher education for an outbreak of COVID-19. J Emerg Manag. 2020 18(2):183-184. doi:10.5055/jem.2020.0463. 


\begin{tabular}{|c|c|c|c|c|c|}
\hline \multirow{2}{*}{$\begin{array}{l}\text { New Prescription } \\
\text { Item }\end{array}$} & \multirow[b]{2}{*}{ Score } & \multicolumn{2}{|l|}{ OTC Request } & \multicolumn{2}{|l|}{ Refill Prescription } \\
\hline & & Item & Score & Item & Score \\
\hline Opening & & Opening & & Opening & \\
\hline Introduce yourself & 2 & Introduce yourself & 2 & Introduce yourself & 2 \\
\hline State purpose of counseling & 2 & Any previous consult with Dr & 2 & State the purpose of counseling & 2 \\
\hline Information Gathering & & Information Gathering & & Information Gathering & \\
\hline Assess present knowledge about medication & 2 & Check for previous treatment & 1 & Check for compliance & 2 \\
\hline and condition & & Check for onset & 1 & & \\
\hline Assess patient allergies & 2 & Check for symptoms & 1 & Check for side effects & 2 \\
\hline & & Check for other associated factors & 1 & & \\
\hline Information Giving & & Information Giving & & Information Giving & \\
\hline Name and group of medications it belongs to & 1 & Name and group of medications it belongs to & 1 & Side effect handling & 2 \\
\hline How medication works & 1 & How medication works & 1 & & \\
\hline How to take medication & 1 & How to take medication & 2 & Compliance counseling-finishing & 2 \\
\hline Most common side effects & 1 & Most common side effects & 1 & antibiotic & \\
\hline Side effect handling & 1 & Side effect handling & 1 & Emphasizing how to take & 2 \\
\hline Compliance counseling & 1 & & & & \\
\hline Closing & & Closing & & Closing & \\
\hline Recap & 1 & Recap & 1 & Recap & 1 \\
\hline Encourage questions & 1 & Encourage questions & 1 & Encourage questions & 1 \\
\hline Monitoring and revisit & 1 & Monitoring and revisit & 1 & Monitoring and revisit & 1 \\
\hline Communication & & Communication & & Communication & \\
\hline Place, tone, and volume & 1 & Place, tone, and volume & 1 & Place, tone, and volume & 1 \\
\hline Appropriate language & 1 & Appropriate language & 1 & Appropriate language & 1 \\
\hline Eye contact & 1 & Eye contact & 1 & Eye contact & 1 \\
\hline
\end{tabular}


Table 2. Students' Assessment Scores in Communication Skills in Pharmacy Course ( $\mathrm{N}=79)$

\section{Assessments}

Mean (\%) \pm SD

First quiz and midterm (30 points)

Counseling roleplay via Zoom teleconference (20 points)

Opening (four points)

Information gathering (four points)

Information giving (six points)

Closing (three points)

Overall communication skills (three points)

$25.9(86.3) \pm 2.4$

$17.4(87) \pm 2.1$

$3.6(90) \pm 0.7$

$3.2(80) \pm 1.1$

$4.7(78.3) \pm 1.2$

$2.8(93.3) \pm 0.5$

$2.9(96.7) \pm 0.4$

$17.8(89) \pm 1.8$

Assignment on assertive behavior (20 points)

$21.8(72.7) \pm 4.6$

Final examination (30 points) 


\begin{tabular}{|c|c|c|c|c|c|c|c|c|c|c|c|}
\hline \multirow{2}{*}{ Survey items } & \multicolumn{10}{|c|}{ Response Distribution n (\%) } & \multirow[b]{2}{*}{$\begin{array}{c}\text { Weighted } \\
\text { Mean } \\
\end{array}$} \\
\hline & \multicolumn{2}{|c|}{$\begin{array}{l}\text { Strongly } \\
\text { disagree }\end{array}$} & \multicolumn{2}{|c|}{ Disagree } & \multicolumn{2}{|c|}{ Undecided } & \multicolumn{2}{|c|}{ Agree } & \multicolumn{2}{|c|}{$\begin{array}{c}\text { Strongly } \\
\text { Agree } \\
\end{array}$} & \\
\hline \multicolumn{12}{|l|}{ Case content } \\
\hline The cases assessed specific knowledge areas & 1 & $(1.8)$ & 1 & $(1.8)$ & 1 & $(1.8)$ & 26 & $(48.2)$ & 25 & $(46.3)$ & 4.4 \\
\hline The cases highlighted my areas of weakness & 2 & $(3.7)$ & 3 & (5.6) & 9 & $(16.7)$ & 17 & $(31.5)$ & 23 & $(42.6)$ & 4.0 \\
\hline The cases covered a range of counseling skills & 1 & $(1.8)$ & 0 & $(0.0)$ & 3 & $(5.6)$ & 22 & $(40.7)$ & 28 & $(51.8)$ & 4.4 \\
\hline The case scenario given to me was sufficient for the required task & 2 & $(3.7)$ & 0 & $(0.0)$ & 7 & $(13.0)$ & 19 & $(35.2)$ & 26 & $(48.2)$ & 4.2 \\
\hline The cases provided me with opportunities to enhance my knowledge $\&$ confidence & 1 & $(1.8)$ & 0 & $(0.0)$ & 2 & $(3.7)$ & 24 & $(44.4)$ & 27 & $(50.0)$ & 4.4 \\
\hline The counseling roleplay evaluated my knowledge & 1 & $(1.8)$ & 1 & $(1.8)$ & 6 & $(11.1)$ & 17 & $(31.5)$ & 29 & $(53.7)$ & 4.3 \\
\hline The counseling roleplay evaluated my communication skills & 1 & $(1.9)$ & 0 & $(0.0)$ & 2 & $(3.8)$ & 21 & $(40.4)$ & 28 & $(53.8)$ & 4.4 \\
\hline The counseling roleplay being worth $20 \%$ was appropriate & 1 & $(1.8)$ & 1 & (1.8) & 12 & $(22.2)$ & 21 & $(38.9)$ & 19 & $(35.2)$ & 4.0 \\
\hline The counseling roleplay gave me a chance to enhance my counseling skills & 2 & $(3.7)$ & 1 & $(1.8)$ & 8 & $(14.8)$ & 23 & $(42.6)$ & 20 & $(37.0)$ & 4.1 \\
\hline The counseling roleplay assessment was fair & 2 & $(3.8)$ & 3 & $(5.7)$ & 6 & $(11.3)$ & 25 & $(47.2)$ & 17 & $(32.1)$ & 4.0 \\
\hline The counseling roleplay was more stressful than written examinations & 5 & $(9.3)$ & 14 & $(25.9)$ & 8 & $(14.8)$ & 19 & $(35.2)$ & 8 & $(14.8)$ & 3.2 \\
\hline \multicolumn{12}{|l|}{ Logistics } \\
\hline The counseling roleplay was well administered & 1 & $(1.9)$ & 1 & $(1.9)$ & 2 & $(3.8)$ & 27 & $(51.9)$ & 21 & $(40.4)$ & 4.3 \\
\hline I was made aware of what I needed to do during counseling roleplay & 1 & $(1.9)$ & 2 & (3.8) & 3 & $(5.8)$ & 20 & $(38.5)$ & 26 & $(50.0)$ & 4.4 \\
\hline The timetable of roleplay was available to me in advance & 1 & $(1.9)$ & 1 & $(1.9)$ & 6 & $(11.5)$ & 17 & $(32.7)$ & 27 & $(51.9)$ & 4.3 \\
\hline Use of Zoom teleconferencing did not affect the quality of my counseling & 3 & $(5.8)$ & 3 & (5.8) & 9 & $(17.3)$ & 17 & $(32.7)$ & 20 & $(38.5)$ & 3.9 \\
\hline The quality of internet connection during roleplay through Zoom was adequate & 1 & $(1.9)$ & 3 & (5.8) & 5 & $(9.6)$ & 24 & $(46.2)$ & 19 & $(36.5)$ & 4.1 \\
\hline The experience of roleplay was comparable to traditional in-room assessments & 3 & $(5.8)$ & 3 & (5.8) & 7 & $(13.5)$ & 23 & $(44.2)$ & 16 & $(30.8)$ & 3.9 \\
\hline I felt the setting and context were still authentic using Zoom in this assessment & 2 & $(3.9)$ & 3 & $(5.9)$ & 10 & $(19.6)$ & 21 & $(41.2)$ & 15 & $(29.4)$ & 3.9 \\
\hline Having video recording option in Zoom was preferred to review my performance & 2 & $(3.8)$ & 2 & (3.8) & 12 & $(23.1)$ & 20 & $(38.5)$ & 16 & $(30.8)$ & 3.9 \\
\hline \multicolumn{12}{|l|}{ Satisfaction with counseling roleplay via Zoom } \\
\hline I am satisfied with online counseling roleplay via Zoom & 2 & $(3.8)$ & 2 & (3.8) & 9 & $(17.0)$ & 22 & $(41.5)$ & 18 & $(34.0)$ & 4.0 \\
\hline Counseling roleplay via Zoom was stimulating & 2 & $(3.8)$ & 2 & (3.8) & 6 & $(11.3)$ & 24 & $(45.3)$ & 19 & $(35.8)$ & 4.0 \\
\hline I enjoyed being assessed using counseling roleplay via Zoom & 2 & $(3.8)$ & 2 & (3.8) & 6 & $(11.3)$ & 24 & $(45.3)$ & 19 & $(35.8)$ & 4.0 \\
\hline The counseling roleplay via Zoom was worth my time & 2 & $(3.8)$ & 2 & (3.8) & 7 & $(13.2)$ & 23 & $(43.4)$ & 19 & $(35.8)$ & 4.0 \\
\hline I look forward to doing more roleplay via Zoom in the future & 2 & $(3.8)$ & 5 & $(9.4)$ & 11 & $(20.8)$ & 17 & $(32.1)$ & 18 & $(34.0)$ & 3.8 \\
\hline
\end{tabular}

